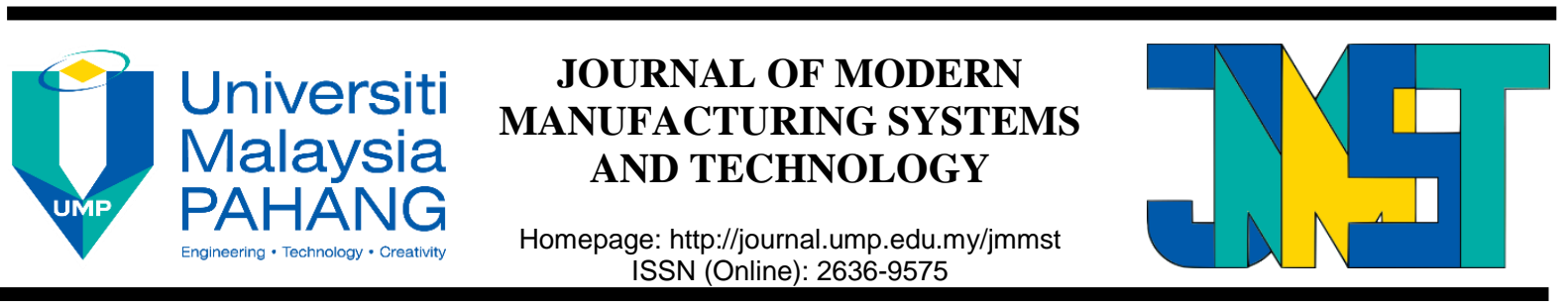

\title{
Performance evaluation of wire electrical discharge machining on Titanium Alloy
}

Tan Jun Qi ${ }^{1 *}$ and Mohd Yazid Abu ${ }^{1+}$

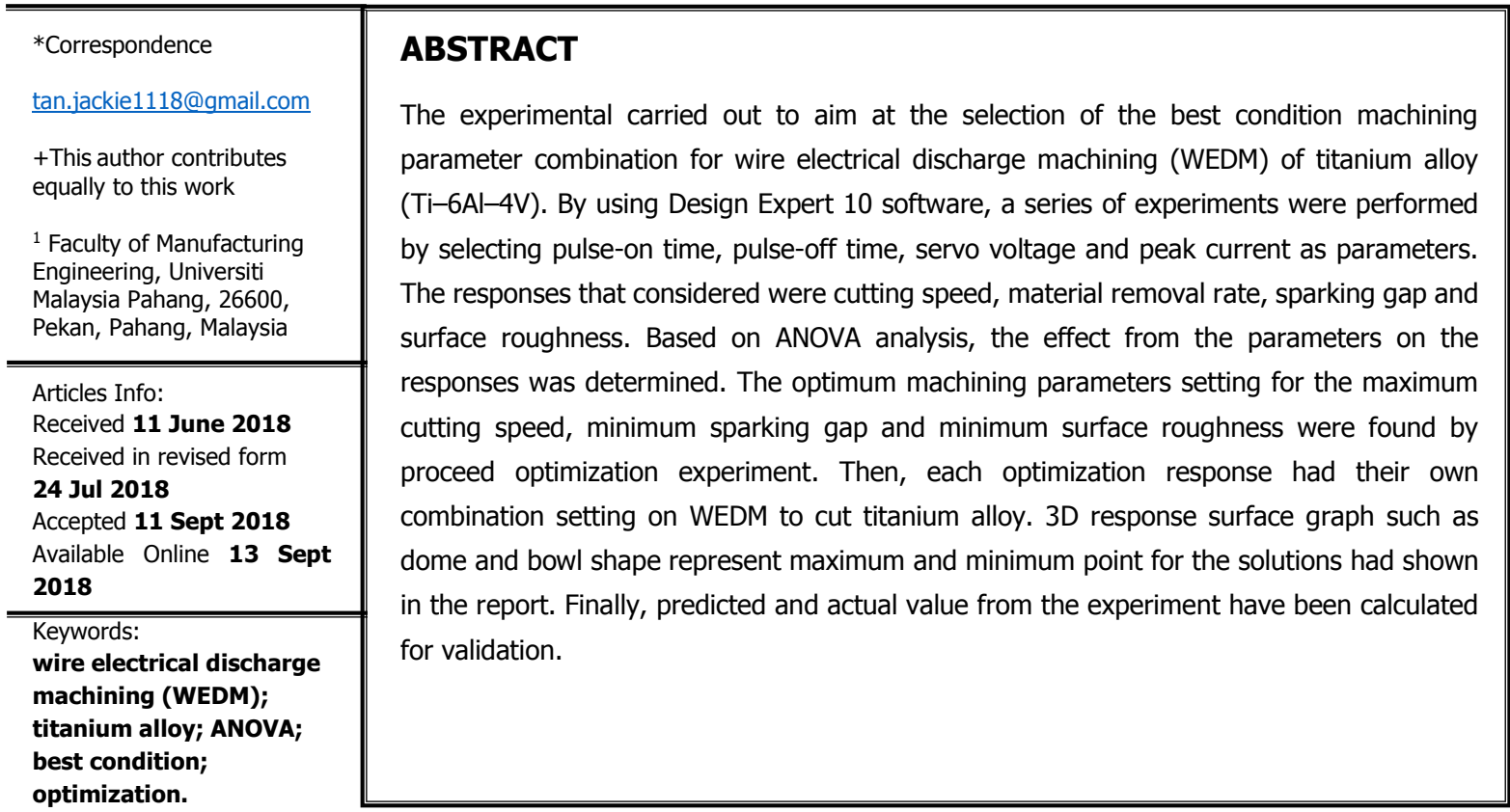

\section{INTRODUCTION}

Wire electrical discharge machining (WEDM) arose since 1960s. WEDM had been discovered while replacing machined electrode used in EDM. WEDM used non- conventional cutting method to cut workpieces with complex profiles. WEDM used a continuous travelling wire electrode to cut the materials. The electrode will create spark with the workpiece to cut using electrical current that the process is immersed inside dielectric fluid [1].

Two types of cutting tool common being used are copper wire and brass wire. Copper wire was the original wire used for WEDM due to the high electrical conductivity. Copper should be the ideal WEDM wire but due to the both tensile strength and flush ability is low level. Brass wire, mixture alloy between $\mathrm{Cu}$ and Zn nowadays become the most commonly used wire for WEDM. Most of the manufacturing factory will chose brass wire due to the low cost comparing with copper wire. The mixture of zinc will improved flush ability of WEDM, thus some manufacturer offer brass wire which is Cu63\%Zn37\%.Zinc that mix with copper will decrease the conductivity but flush ability show more important because it related to the performance of wire while cut the workpiece [2].

There are many types of titanium alloy but the Ti-6Al-4V is the widely type titanium alloys used e.g. aerospace, medical, dental, chemical processing and aviation industries. The two phases $(\alpha+\beta)$ Ti-6Al$4 \mathrm{~V}$ (Ti64) alloy contain aluminium (6 wt \%) stabilizes $\alpha$ phase and vanadium (4 wt \%) stabilizes $\beta$ phase. The excellent combination of strength, good corrosion resistance, and excellent biocompatibility made Ti64 
chosen. Before safely usable parts of titanium alloy (Ti-6Al-4V) can be manufactured by WEDM, the properties of Ti64 need to be study and understand. The optimum values for different process parameters in WEDM are important to improve the machining performance [3].

WEDM is a machine that produce precise and low volume product demands thus the manufacturing process of the WEDM is important [4]. Eight machining parameters are chosen as the processing factors such as pulse-on time(ON), pulse-off time (OFF), servo voltage (SV), cutting radius of work piece (AN), water flow(WL), duration for arc ON (AN), duration arc off(AFF) and wire feed (WF) [5].

Researchers have sought for many ways to improve the performance characteristic namely dimensional accuracy, cutting speed, surface roughness, material removal rate, spark gap and kerf width. The complex, stochastic nature and numbers of variable involved in WEDM operation cause full potential utilization of the process incomplete solved [6]. The abilities of WEDM to produce part with precision and intricate profiles had made WEDM machining popular used in manufacturing factory. The WEDM have a wide application area including medical implants, aerospace industry, electronic industry, automobile industries, etc. Titanium and its alloy wide used in several of industries. Recently, biomedical and medical field had selected titanium for their field because it capable to be joint with body tissue, strong, flexible, corrosion immune and bone growth consistent [7].

\section{METHODOLOGY}

The experiment was performed on a Wire-EDM SODICK VZ300L to machine a piece of Titanium alloy Ti6Al4V with dimension $100 \mathrm{~mm} \times 100 \mathrm{~mm} \times 5 \mathrm{~mm}$. The wire electrode chosen is a brass wire electrode with diameter of $0.20 \mathrm{~mm}$. In present experiment, pulse-on time, pulse-off time, servo voltage and peak current are the choose as the study parameters. Each parameter had classified in three stage low, centre and high level to obtain the most significant parameter that effect the respond. ANOVA is used to identify the most significant parameter. The best optimum setting parameters that effect on the respond can be introduce. The Table 1 show the level values for each parameter while machining. The level values for pulse-on time, pulse-off time and peak current are based on [1] research on material titanium alloys (Ti$6 \mathrm{Al}-4 \mathrm{~V}$ ). The level of servo voltage is based on [8] experiment on material AISI304. Table 2 shows the constant parameter values while WEDM titanium alloys. The values of the constant values parameters taken directly form the monitor WEDM.

Table 1: Factors and their levels.

\begin{tabular}{|c|c|c|c|c|c|c|c|}
\hline \multicolumn{3}{|c|}{ Parameters } & Low & & \multicolumn{2}{|c|}{ Centre } & $\mathrm{Hi}$ \\
\hline \multicolumn{3}{|c|}{ Pulse-on time, $\mathrm{T}_{\text {on }}(\mu \mathrm{s})$} & 49 & & 100 & & 14 \\
\hline \multirow{2}{*}{\multicolumn{3}{|c|}{$\begin{array}{l}\text { Pulse-off time, } \mathrm{T}_{\text {off }}(\mu \mathrm{s}) \\
\text { Servo voltage, } \mathrm{SV} \text { (volt) }\end{array}$}} & 24 & & 40 & & 5 \\
\hline & & & 15 & & 25 & & \\
\hline \multicolumn{2}{|c|}{ Peak current, IP (amp) } & & 9 & & 17 & & 2 \\
\hline eters & \multicolumn{7}{|c|}{ Table 2: Constant parameters. } \\
\hline $\begin{array}{l}\text { Parameters } \\
\text { Variables }\end{array}$ & \begin{tabular}{|l|l|} 
HRP & MAU \\
000 & 590 \\
\end{tabular} & 6.0 & $\begin{array}{l}\text { WVK } \\
020\end{array}$ & $\frac{\mathrm{V} I}{120}$ & & $\frac{\mathrm{WVP}}{050}$ & $\begin{array}{l}\mathrm{SF} \\
52\end{array}$ \\
\hline
\end{tabular}

The Equation (1) is shows to calculate the material removal rate.

$$
\operatorname{MRR}=\mathrm{k} \times \mathrm{t} \times \mathrm{v}_{\mathrm{c}} \times \rho
$$

Where MRR represent the material removal rate $\left[\mathrm{mm}^{3} / \mathrm{min}\right], \mathrm{k}$ is the kerf width of the cutting material $[\mathrm{mm}], t$ is the thickness of the material workpiece $[\mathrm{mm}], \mathrm{v}_{\mathrm{c}}$ is set as the cutting speed $[\mathrm{mm} / \mathrm{min}]$, and $\rho$ is the density of the workpiece $\left[\mathrm{g} / \mathrm{mm}^{3}\right]$. The Equation (2) performed to calculate spark gap.

$$
\text { Spark gap }=\frac{(\text { kerf width }- \text { wire diameter })}{2} \mathrm{~mm}
$$

The kerf width of the workpiece is measure by using optical video measuring system machine. The constant diameter of the wire electrode used is $0.20 \mathrm{~mm}$ [9]. The cutting speed values of the workpiece are recorded while machining. The reading of the cutting speed can be recorded directly form the monitor of the WEDM machine. The surface roughness of the workpiece measure by using SURFCOM 130 surface measuring machine. All the measurement and the calculation for each response tested by ANOVA to obtain significant results. 
The titanium alloy surface is marked with 20 parts with dimension $5 \mathrm{mmx} 5 \mathrm{~mm}$ by using permanent marker pen. The side of titanium alloy is cut in $5 \mathrm{~mm}$ and this step need to repeat 20 times to produce 20 lines. The 20 lines are cut base on the different combination of parameters that generated by Design Expert 10. The kerf width will be measure using optical video measuring system machine. All the kerf width measurement will be repeated three times to obtain average measurement kerf width for the 20 samples. The measurement of kerf width can then use for calculate the material removal rate (MRR) and sparking gap. Each sample have different kerf width thus the material removal rate (MRR) and sparking gap is calculated one by one. The cutting speed for each sample can be obtain through the monitor of the WEDM machine. The workpiece will be place back to the machine and continue cut out the shape of the samples with dimension $5 \mathrm{~mm} \times 5 \mathrm{~mm} \times 5 \mathrm{~mm}$. The samples are cut one by one to ensure the samples do not mix up. The 20 pieces of samples are cut out as show in Figure 1. The 20 samples will be transfer to the SURFCOM 130 surface measuring machine for the surface roughness measurement purpose.

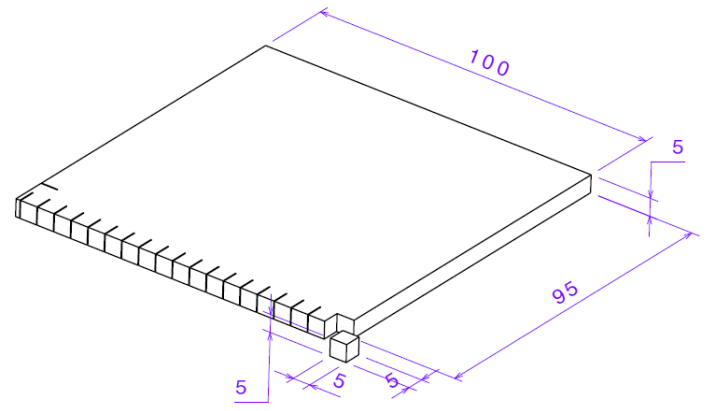

Figure 1: Titanium alloys is cut out 20 pieces of samples $(5 \mathrm{mmx} 5 \mathrm{~mm} \times 5 \mathrm{~mm})$.

\section{RESULT AND DISCUSSION}

After proceed the experiment, the data get from each response insert into software Design Expert 10. The responses that stated are cutting speed, material removal rate, sparking gap and surface roughness. Figure 2 shows the result for all responses.

\begin{tabular}{|c|c|c|c|c|c|c|c|c||}
\hline & \multicolumn{9}{|c|}{ Factors } & \multicolumn{4}{c|}{ Responses } \\
\hline STD & $\begin{array}{c}\text { Pulse-on } \\
\text { time/s }\end{array}$ & $\begin{array}{c}\text { Pulse- } \\
\text { off } \\
\text { time/s }\end{array}$ & $\begin{array}{c}\text { Servo } \\
\text { voltage/V }\end{array}$ & $\begin{array}{c}\text { Peak } \\
\text { current/A }\end{array}$ & $\begin{array}{c}\text { Cutting } \\
\text { speed/ } \\
\mathrm{mm} / \mathrm{min}\end{array}$ & $\begin{array}{c}\text { Material } \\
\text { removal } \\
\text { rate/ } \\
\mathrm{g} / \mathrm{min}\end{array}$ & $\begin{array}{c}\text { Sparking } \\
\text { gap /mm }\end{array}$ & $\begin{array}{c}\text { Surface } \\
\text { roughness } \\
\text { /mm }\end{array}$ \\
\hline 1 & 49 & 24 & 15 & 9 & 0.8958 & 5.0582 & 0.0278 & 2.576 \\
\hline 2 & 145 & 24 & 15 & 9 & 0.6687 & 3.9000 & 0.032 & 2.227 \\
\hline 3 & 49 & 52 & 15 & 9 & 0.1831 & 1.0622 & 0.0313 & 2.217 \\
\hline 4 & 145 & 52 & 15 & 9 & 0.1944 & 1.0800 & 0.0257 & 2.19 \\
\hline 5 & 49 & 24 & 35 & 9 & 0.7306 & 4.2190 & 0.0307 & 2.816 \\
\hline 6 & 145 & 24 & 35 & 9 & 0.6054 & 3.6419 & 0.0361 & 2.137 \\
\hline 7 & 49 & 52 & 35 & 9 & 0.1876 & 1.1400 & 0.0375 & 2.327 \\
\hline 8 & 145 & 52 & 35 & 9 & 0.1923 & 1.1628 & 0.0368 & 2.693 \\
\hline 9 & 49 & 24 & 15 & 21 & 5.2000 & 36.1308 & 0.0572 & 3.033 \\
\hline 10 & 145 & 24 & 15 & 21 & 5.1991 & 39.1005 & 0.0702 & 3.072 \\
\hline 11 & 49 & 52 & 15 & 21 & 5.1990 & 37.8359 & 0.0647 & 3.047 \\
\hline 12 & 145 & 52 & 15 & 21 & 5.1992 & 38.8025 & 0.0689 & 3.083 \\
\hline 13 & 49 & 24 & 35 & 21 & 5.2002 & 34.6382 & 0.0507 & 3.353 \\
\hline 14 & 145 & 24 & 35 & 21 & 5.1998 & 40.0596 & 0.0743 & 3.189 \\
\hline 15 & 49 & 52 & 35 & 21 & 5.1995 & 39.2759 & 0.0709 & 3.26 \\
\hline 16 & 145 & 52 & 35 & 21 & 5.1983 & 39.0945 & 0.0702 & 3.203 \\
\hline 17 & 97 & 38 & 25 & 15 & 4.6248 & 28.6796 & 0.0403 & 2.349 \\
\hline 18 & 97 & 38 & 25 & 15 & 4.6632 & 28.0005 & 0.0359 & 2.279 \\
\hline 19 & 97 & 38 & 25 & 15 & 4.5262 & 27.0779 & 0.0354 & 2.274 \\
\hline 20 & 97 & 38 & 25 & 15 & 4.6368 & 28.3805 & 0.0385 & 2.406 \\
\hline
\end{tabular}

Figure 2: Results for all responses.

\section{Cutting speed}

ANOVA analysis for cutting speed of the WEDM while cutting titanium alloy. The p-value for model of the respond cutting speed resulted $<0.0001$. The $p$-value that is smaller than 0.05 thus indicates as a significant independent factor. The model must be significant to prove that the parameters shows significant effect on responds. The factors that affect the response demonstrated in a Pareto charts in Figure 3. The bar length for each factor and the interaction are arranged proportional. The orange \& blue color bar show positive and negative effects respectively. The positive effects mean the effect shows more significant 
values as the factors keep increase. The negative effects mean that when the factors decrease, the respond shows more significant value. The Design Experts plots the parameters effects in decreasing order due to that value of the effects. From the Pareto chart, factor (D) peak current shows the highest value of 61.46 among others factors. The second highest factor are factor (B) pulse-off time. Pulse-off time show in blue bar thus it has negative effect on the respond. It is possible to verify that peak current shows most significant effect on the respond cutting speed follow by pulse-off time. The bar chart is plot due to corresponding contribution probabilities.

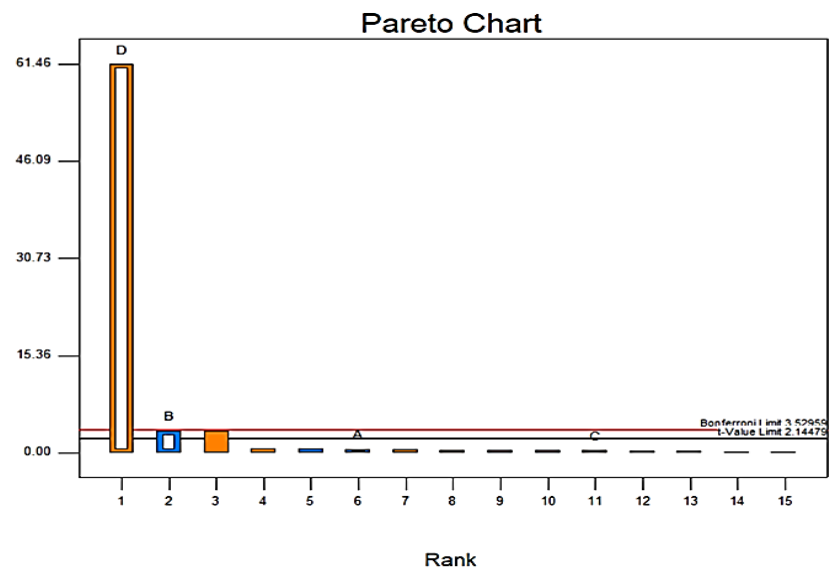

Figure 3: Pareto chart for cutting speed;(A) Pulse-on time; (B) Pulse-off time; (C) Servo voltage; (D) Peak current; (Orange) Positive effect; (Blue) Negative effect.

\section{Material removal rate}

The p-value from the ANOVA analysis shows the model is $<0$. 0001.Thus, the model is significant due to the p-value is less than 0. 005.The model for material removal rate is accepted to be independent factor. The Figure 4 shown the pareto chart for the material removal rate. The bar chart is arranged the factors due to the percentage of contribution of the effect. Factor (D) peak current shows the highest value of 42.74. Peak current shows positive effect on the respond material removal rate thus the respond result more significant effect when the peak current increase. Factor (C) servo voltage show the lowest significant effect on the respond. Factor (A) pulse-on time is the second significant effect on the respond. Conclude, peak current is the most significant factors to the respond follow by pulse-on time.

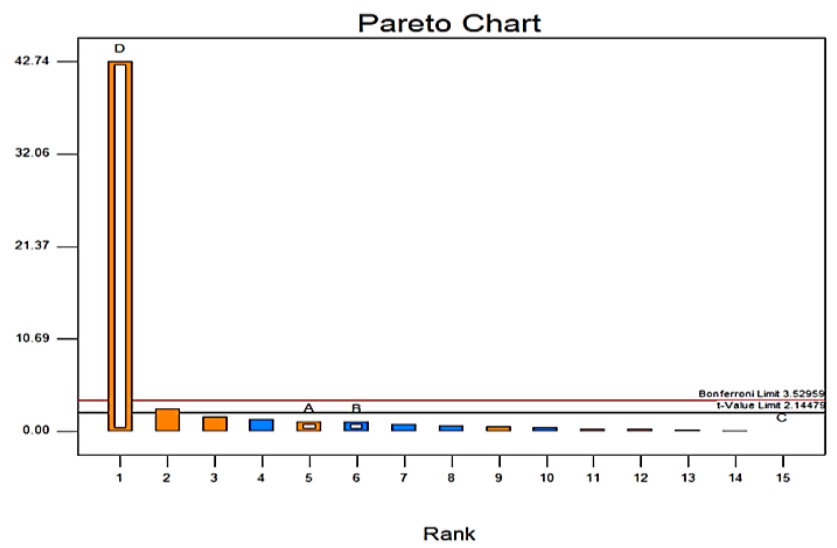

Figure 4: Pareto chart for material removal rate;(A) Pulse-on time; (B) Pulse-off time; (C) Servo voltage; (D) Peak current; (Orange) Positive effect; (Blue) Negative effect.

\section{Sparking gap}

The p-value for the sparking gap model is $<0.0001$ therefore it is a significant model. The p-value for the model need to be less than 0.005 to get a significant model. The Pareto chart for the sparking gap is shows in Figure 5. Factor (D) peak current shows the highest bar length and it is positive effect on the effect. The second factor is the interaction factors $(A B)$ between factor $(A)$ pulse-on time and (B) pulse-off time. The interaction $(A B)$ shows the negative effect on the respond. The following factors after interaction $(A B)$ 
are factor (A) pulse-on time, interaction factors (AD) between pulse-on time and peak current, factor (C) servo voltage and factor (B) pulse-off time respectively. The main factors such as pulse-on time, pulse-off time, servo voltage, and peak current must be selected in every effect list. The interaction factors are selected due to the contribution percentage more than $1 \%$. All the selected factors show positive effect on the respond except interaction $(\mathrm{AB})$.

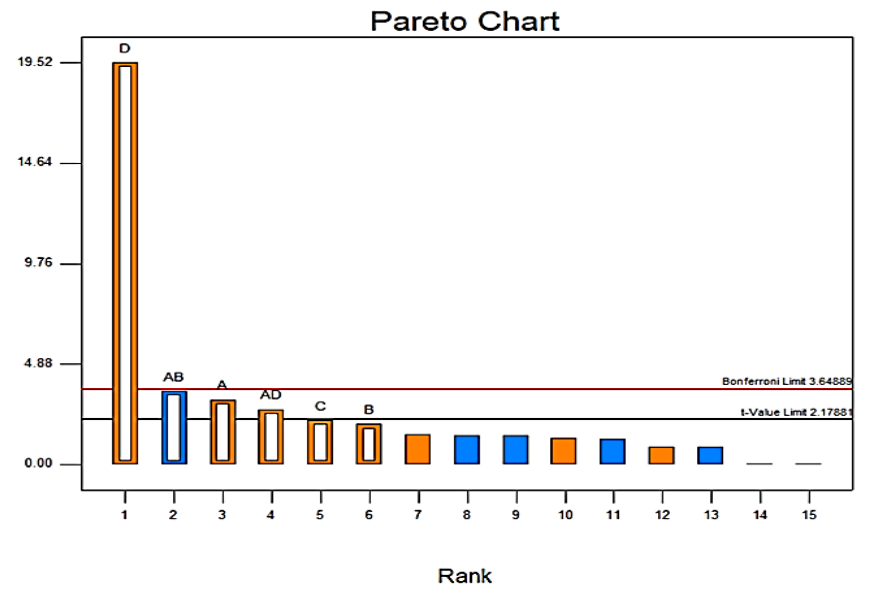

Figure 5: Pareto chart for sparking gap;(A) Pulse-on time; (B) Pulse-off time; (C) Servo voltage; (D) Peak current; (Orange) Positive effect; (Blue) Negative effect.

The mode graphs for interaction factors that effect on the sparking gap are show in Figure 6 and Figure7. From Figure 6, it can be observed that it has two lines. The black rectangle dot line show that the factor (B) pulse-off time is at $24 \mu$ s.Meanwhile, the red triangle shape dot line represents the pulse-off time at $52 \mu \mathrm{s}$. While factor (A) pulse-on time increase at the time of pulse-off time at $52 \mu \mathrm{s}$, the sparking gap slightly decreases.

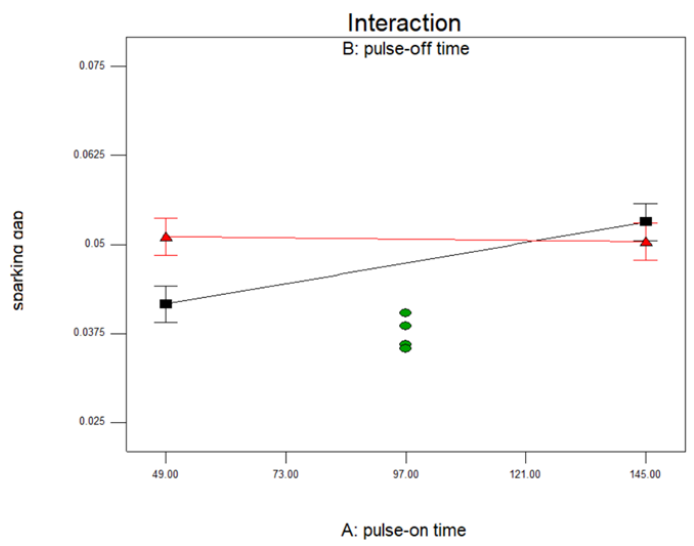

Figure 6: Model graph of interaction between pulse-on time and pulse-off time.

Figure7 shows the interaction between factor (A) pulse-on time and factor (D) peak current. The black rectangle dot and red triangle dot line show peak current at 9A and 21A respectively. When pulse-on time increase from $49 \mu$ s to $145 \mu \mathrm{s}$ at $9 \mathrm{~A}$ peak current, the sparking gap increase slightly. When peak current at $21 \mathrm{~A}$ and the pulse-on time increases, the sparking gap also increase. The gradient of sparking gap graph increase in peak current $21 \mathrm{~A}$ is higher than peak current at $9 \mathrm{~A}$. 


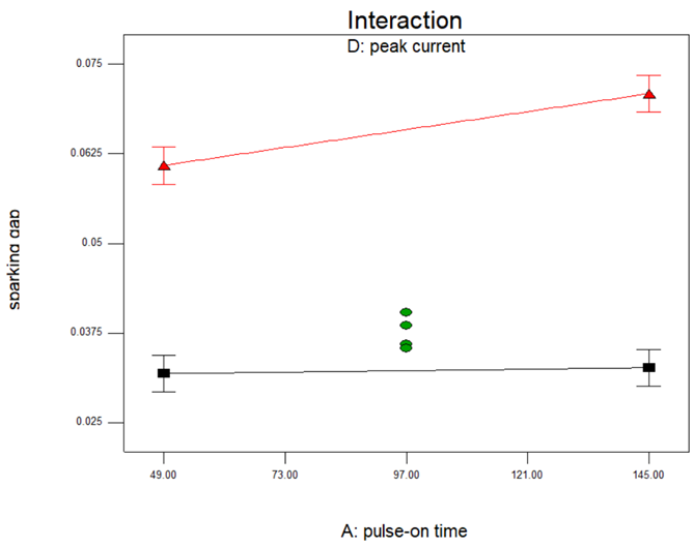

Figure 7: Model graph of interaction between pulse-on time and peak current.

\section{Surface roughness}

The model of the surface roughness is significant due to its $p$-value less than 0.05 . The p-value for model surface roughness is $<0.01$. The model must be significant. Figure 8 shows the Pareto chart for surface roughness. The factor (D) peak current shows the highest value of 15.90. The peak current show positive effect on the surface roughness. When peak current more increase, the more significant effect on surface roughness. The following factors are arranged due to the value of effect such as factor (C) servo voltage, interaction factors $(A B)$, interaction factors $(A B D)$, factor $(A)$ pulse-on time, interaction factors $(A B C)$, interaction factors $(A D)$, factor $(B)$ pulse-off time, interaction factors $(B C)$, interaction factors (BD) and interaction factors $(A C)$. Interaction factors $(A B D)$, factor $(A)$, factor $(B)$ and interaction factors $(A C)$ are negative effect on the respond surface roughness.

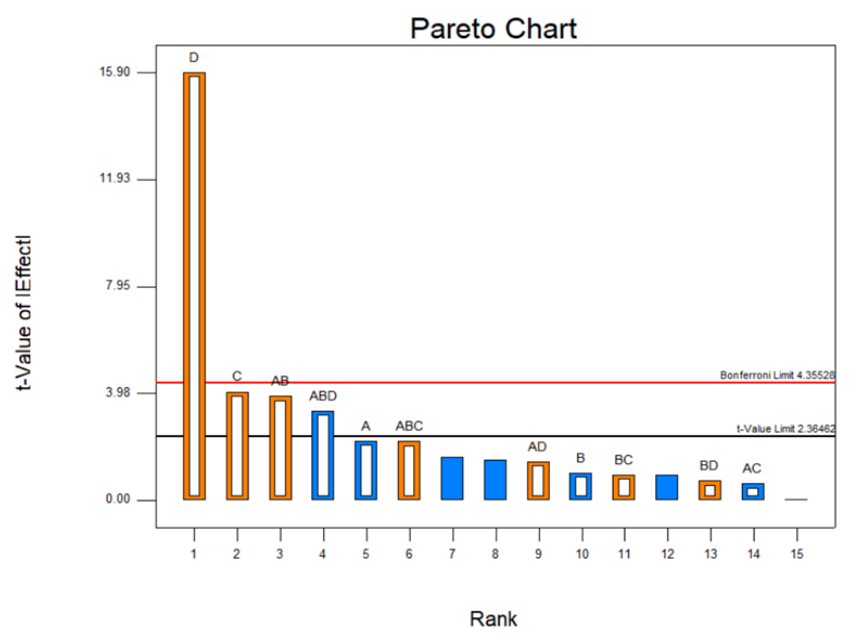

Figure 8: Pareto chart for surface roughness;(A) Pulse-on time; (B) Pulse-off time; (C) Servo voltage; (D) Peak current; (Orange) Positive effect; (Blue) Negative effect.

Figure 9 shows the interaction between factor (A) pulse-on time and factor (B) pulse-off time. The black rectangle dot line represents the pulse-off time at $24 \mu$ s. For the line that have red triangle dot represents the pulse-off time at $52 \mu \mathrm{s}$. The surface roughness decreases when the pulse-on time increase at the pulse-off time $24 \mu \mathrm{s}$. When the pulse-off time is at $52 \mu$ s and the pulse-on time at increase stage, the surface roughness increases. There has an interaction between two situations. 


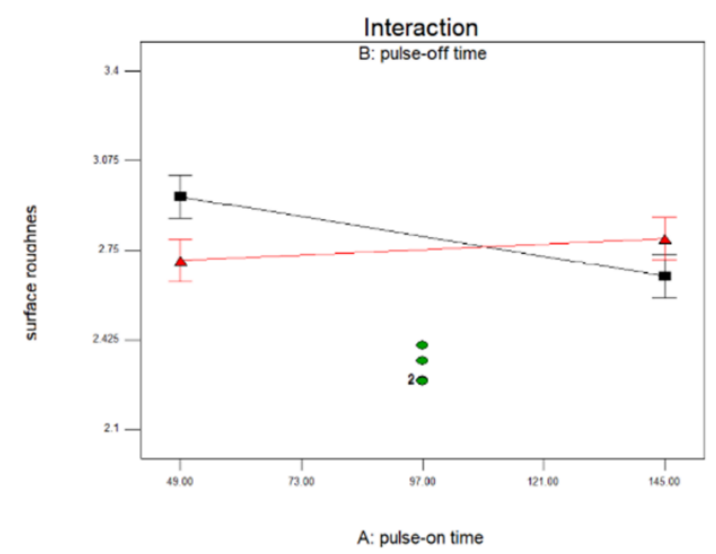

Figure 9: Model graph for interaction factor between A \& B.

The interaction between factor (A) pulse-on time and factor (C) servo voltage is shown in Figure 10. Servo voltage at the stage of $15 \mathrm{~V}$ and $25 \mathrm{~V}$ are show in black rectangle dot and red triangle dot line respectively. The surface roughness decreases when the pulse-on time increase at both $15 \mathrm{~V}$ and $25 \mathrm{~V}$ servo voltage. As the pulse-on time continuous increase, an interaction between factors occurs in both different servo voltages.

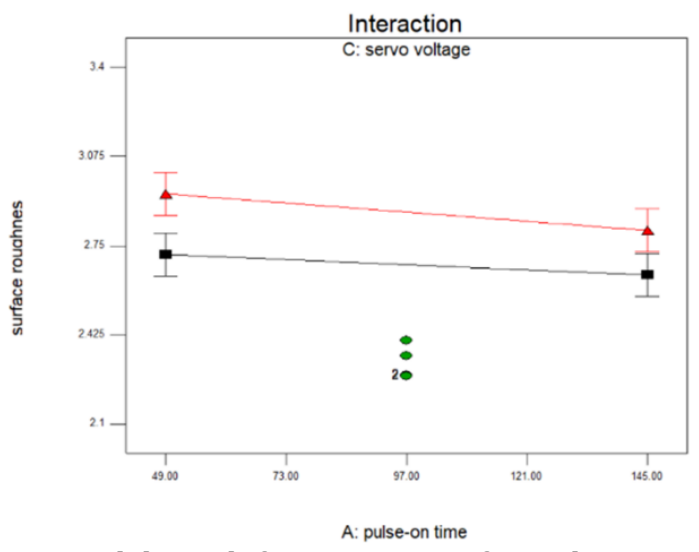

Figure 10: Model graph for interaction factor between A \& C.

The Figure 11 shows the model graph of the interaction between factor (A) pulse-on time and factor (D) peak current. Peak current at $9 \mathrm{~A}$ is represent by black rectangle dot line and for $21 \mathrm{~A}$ is represent as a red triangle dot line. Both $9 \mathrm{~A}$ and $21 \mathrm{~A}$ peak current effect surface roughness decrease as the pulse-on time increase. The slope graph of the $9 \mathrm{~A}$ show steeper compare to $21 \mathrm{~A}$ graph.

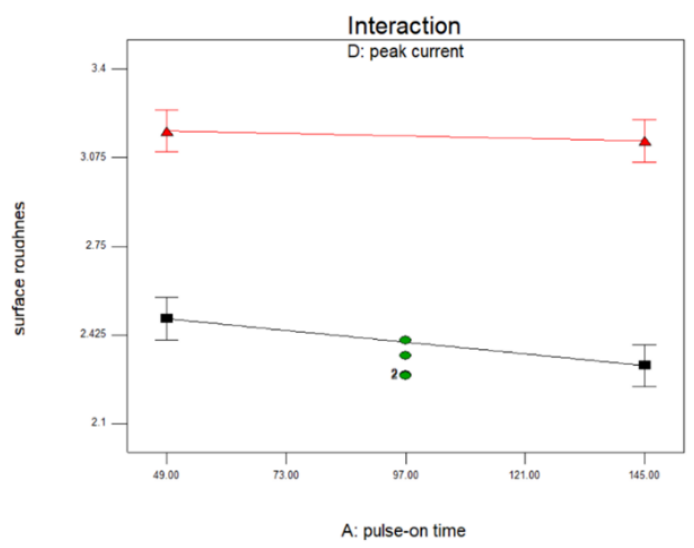

Figure 11: Model graph for interaction factor between A \& D.

The Figure 12 is represented the model graph for interaction between factor (B) pulse-off time and factor (C) servo voltage. Servo voltage that with $15 \mathrm{~V}$ and $35 \mathrm{~V}$ are both represent by black rectangle dot and red triangle dot line respectively. The surface roughness slightly increases when pulse-off time increase 
with $35 \mathrm{~V}$ of peak current. For $15 \mathrm{~V}$ of peak current, the surface roughness decreases when increase of the pulse-off time.

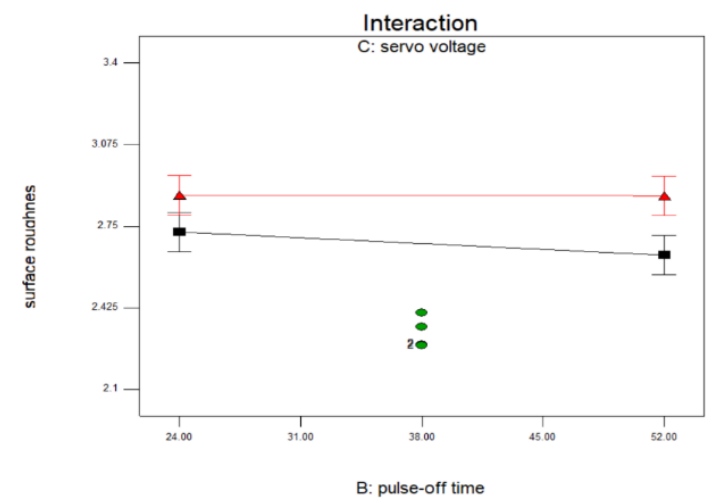

Figure 12: Model graph of interaction between factors B \& C.

The model graph of the interaction between factor (B) pulse-off time and factor (D) peak current is shows in Figure 13. The black rectangle dot line shows the low value of $9 \mathrm{~V}$ peak current. The high value of $21 \mathrm{~V}$ peak current is represent with red triangle dot line. Two lines can be observed from the graph. Both line show decreases of surface roughness when pulse-off time increase. In the $9 \mathrm{~V}$ peak current line show steeper graph than $21 \mathrm{~V}$ peak current.

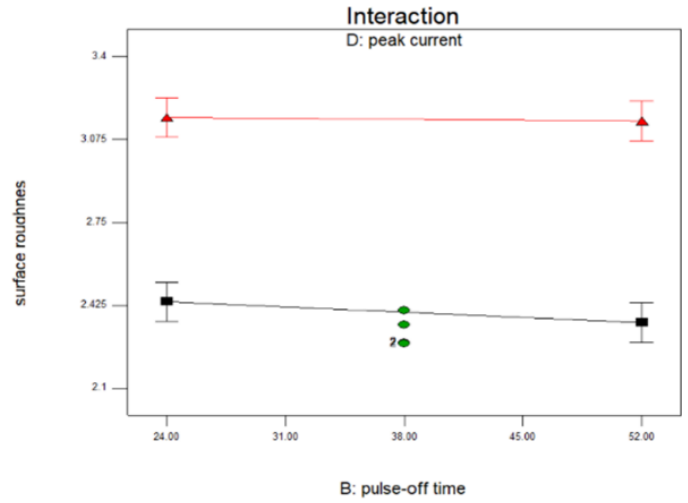

Figure 13: Model graph of interaction between factors B \& D.

After all the responses analysis, each response resulted solution method for the best condition setting. The combination factors between pulse-on time, pulse-off time, peak current, servo voltage to produced best condition for each response. Design Expert resulted more than 1 solution for each response. The ways to select one solution for each response are the desirability need to be the highest among the other solutions and the value of the parameters can be achieved with the equipment. The best condition for each response is show in Table 3.

Table 3: Best condition for each response.

\begin{tabular}{|c|c|c|c|c|c|}
\cline { 2 - 6 } \multicolumn{1}{c|}{} & $\begin{array}{c}\text { Table 3: Best condition for each response. } \\
\text { time/s }\end{array}$ & $\begin{array}{c}\text { Pulse-off } \\
\text { time/s }\end{array}$ & $\begin{array}{c}\text { Servo } \\
\text { voltage/V }\end{array}$ & $\begin{array}{c}\text { Peak } \\
\text { current/A }\end{array}$ & $\begin{array}{c}\text { Value for } \\
\text { responses }\end{array}$ \\
\hline $\begin{array}{c}\text { Cutting speed/ } \\
\mathrm{mm} / \mathrm{min}\end{array}$ & 145 & 52 & 35 & 9 & 0.2878 \\
\hline $\begin{array}{c}\text { Material } \\
\text { removal rate/ } \\
\text { g/min }\end{array}$ & 49 & 52 & 16.71 & 9 & 1.7252 \\
\hline $\begin{array}{c}\text { Sparking gap } \\
\text { /mm }\end{array}$ & 49 & 24 & 15 & 9 & 0.0252 \\
\hline $\begin{array}{c}\text { Surface } \\
\text { roughness } \\
\text { /mm }\end{array}$ & 145 & 24 & 16.12 & 9 & 2.1760 \\
\hline
\end{tabular}


The responses that further optimize are due to the effect on the significant factors. The responses that more than one significant factors need to be optimize. From the ANOVA analysis for each response, it resulted that responses cutting speed, sparking gap and surface roughness can proceed on optimization.

\section{Cutting speed}

From the best condition setting ANOVA analysis for cutting speed, the factors pulse-off time and peak current shows as the significant factors. The p-value for pulse-off time and peak current are 0.0037 and $<0.0001$ respectively. Both of the factors are less than 0.05 thus two factors are significant factors. Pulse-off time and peak current are the significant factors for cutting speed. The range for both factors narrowed. The value for pulse-off time and peak current from best condition setting set as the middle point for the new narrow range. The aim is to found the optimum maximum cutting speed setting. The Table 4 shows the narrow value of both factors.

Table 4: Narrow range value for pulse-off time and peak current.

\begin{tabular}{|c|c|c|c|c|}
\cline { 2 - 5 } \multicolumn{1}{c|}{} & \multicolumn{2}{c|}{ Pulse-off time/s } & \multicolumn{2}{c|}{ Peak current/A } \\
\hline Range & Low & High & Low & High \\
\hline Best conditions & 24 & 52 & 9 & 21 \\
\hline Optimization & 42 & 62 & 4 & 14 \\
\hline
\end{tabular}

The values are key in into Design Expert to generate new combination factors between pulse-off time and peak current. Experiment have been done based on the data generate by the software. The response surface of pulse-on time and peak current affect the cutting speed when cutting titanium alloy shows in Figure 14. The 3D cutting speed shows a dome shape. The maximum optimum solution cutting speed is shown in the maximum point of the dome shape. From the figure, the cutting speed increase when peak current increase. In term of interaction, higher the pulse-on time and peak current will increase the cutting speed.

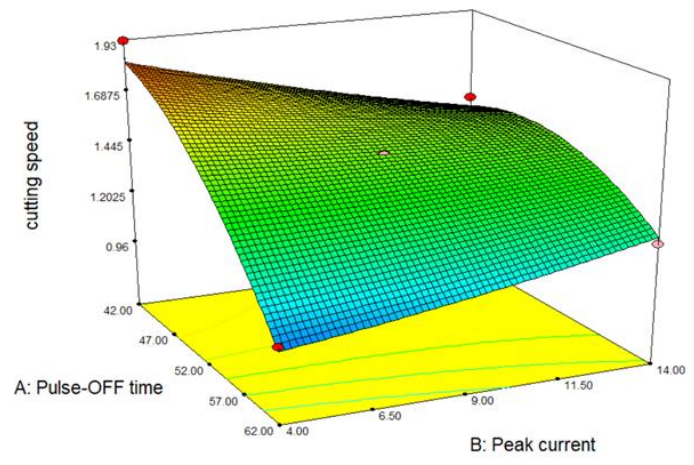

Figure 14: 3D cutting speed affect by pulse-off time and peak current.

\section{Sparking gap}

The ANOVA analysis for sparking gap at best condition shows that factors pulse-on time and peak current are the significant factors. The p-value for pulse-on time and peak current show 0.0084 and $<0.0001$ respectively. Both of the factors are less than 0.005 thus the factors are significant effect on the sparking gap. The range for both factors narrowed to do optimization. The best condition setting value for pulse-on time and peak current effect on the sparking gap are set as midpoint of the narrowed range. The optimum minimum sparking gap is set to be found. The Table 5 shows the narrowed value for pulse-on time and peak current.

Table 5: Narrow range value for pulse-on time and peak current.

\begin{tabular}{|c|c|c|c|c|}
\cline { 2 - 5 } \multicolumn{1}{c|}{} & \multicolumn{2}{c|}{ Pulse-on time/s } & \multicolumn{2}{c|}{ Peak current/A } \\
\hline Range & Low & High & Low & High \\
\hline Best conditions & 49 & 145 & 9 & 21 \\
\hline Optimization & 125 & 165 & 4 & 14 \\
\hline
\end{tabular}


The Figure 15 shows the response surface for sparking gap that effect by the interaction of pulseon time and peak current. The cup shape show that it has a minimum point at the bottom of the shape. The point shows the minimum of the sparking gap. When both pulse-on time and peak current increase, the sparking gap decrease.

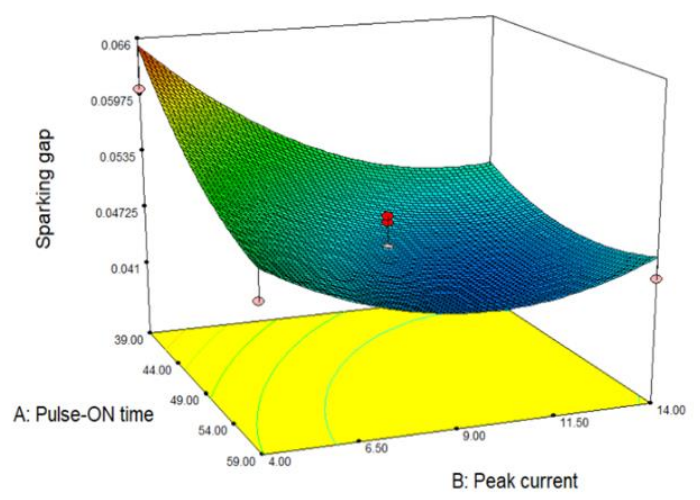

Figure 15: 3D sparking gap affect by pulse-on time and peak current.

\section{Surface roughness}

The ANOVA analysis for the best condition setting surface roughness shows that the factors servo voltage and peak current are the significant factors effect on the surface roughness. The p-value for servo voltage and peak current are 0.005 and $<0.0001$. Both of the factors are less than 0.05 and then both are significant factors. The range for best condition surface roughness narrowed to be optimization. The best condition surface roughness set as the midpoint for the new range. The optimum maximum surface roughness is aim to be found. Table 6 shows the range of servo voltage and peak current after narrowed.

Table 6: Narrow range value for servo voltage and peak current.

\begin{tabular}{|c|c|c|c|c|}
\cline { 2 - 5 } \multicolumn{1}{c|}{} & \multicolumn{2}{c|}{ Servo voltage/V } & \multicolumn{2}{c|}{ Peak current/A } \\
\hline Range & Low & High & Low & High \\
\hline Best conditions & 15 & 35 & 9 & 21 \\
\hline Optimization & 11 & 19 & 4 & 14 \\
\hline
\end{tabular}

Figure 16 shows the response surface for the sparking gap. The 3D surface roughness is effect on factors servo voltage and peak current. The graph shows a dome shape. The dome shape shows that one maximum point at the top of the shape. It shows that the surface roughness is maximum. It can be observed that when both factors servo voltage and peak current increase, the surface roughness increase.

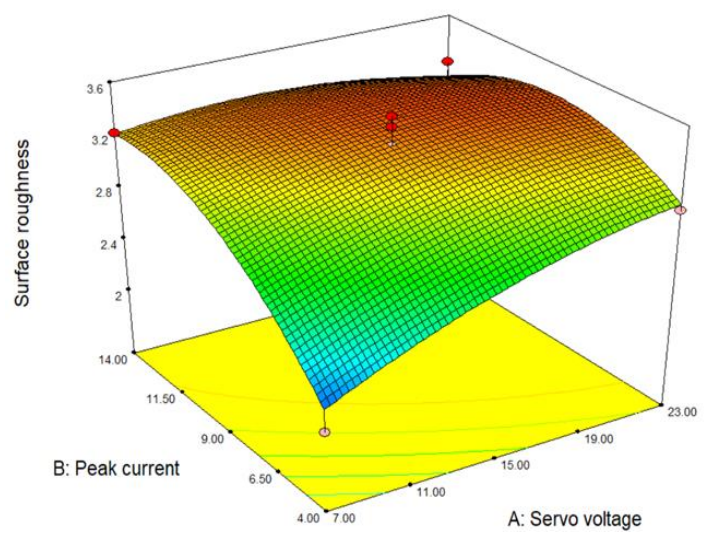

Figure 16: 3D surface roughness affects by servo voltage and peak current.

The Design Expert 10 generate out the solution for each response cutting speed, sparking gap and surface roughness. The solution for optimization are different with the solution generated at best condition. The solution for optimization have been narrowed the range of factors. Table 7 shows the solutions for the optimization response. 
Table 7: Solution for optimization responses.

\begin{tabular}{|c|c|c|}
\hline $\begin{array}{c}\text { Pulse-off time } \\
(\mathrm{s})\end{array}$ & $\begin{array}{c}\text { Peak current } \\
(\mathrm{A})\end{array}$ & $\begin{array}{c}\text { Cutting speed } \\
\text { (mm/min) }\end{array}$ \\
\hline 42 & 4 & 1.824 \\
\hline $\begin{array}{c}\text { Pulse-on time } \\
(\mathrm{s})\end{array}$ & $\begin{array}{c}\text { Peak current } \\
(\mathrm{A})\end{array}$ & $\begin{array}{c}\text { Sparking gap } \\
\text { (mm) }\end{array}$ \\
\hline 54.65 & 10.44 & 0.044 \\
\hline $\begin{array}{c}\text { Servo voltage } \\
(\mathrm{V})\end{array}$ & $\begin{array}{c}\text { Peak current } \\
(\mathrm{A})\end{array}$ & $\begin{array}{c}\text { Surface roughness } \\
\text { (mm) }\end{array}$ \\
\hline 18.64 & 10.31 & 3.399 \\
\hline
\end{tabular}

Confirmation run proceed to verify the optimization solutions. The optimization solution value can be verifying after do the experiment. The solution value for each response used to do the experiment. The predicted value from the software and actual value produced from the experiment compared by calculating the percentage error. The results obtained from the experiment used to calculate the percentage error between the predicted and actual results. Table 8 shows the percentage error between predicted and actual value.

Table 8: Percentage error between predict and actual value.

\begin{tabular}{|l|c|c|c|}
\hline Responses & Predicted & Actual & \% error \\
\hline Cutting speed/mm/min & 1.824 & 1.9146 & 4.96 \\
\hline Sparking gap $/ \mathrm{mm}$ & 0.044 & 0.048 & 9.09 \\
\hline Surface roughness/mm & 3.399 & 3.440 & 1.21 \\
\hline
\end{tabular}

Based on the confirmation run and the validation, the suggested optimization solution was reasonably accurate. The values for percentage of error proved that all the responses are between 1.21 to 9.09 percent.

\section{CONCLUSIONS}

The significant machining parameters pulse-on time, pulse-off time, peak current and servo voltage have verified to its corresponding respond using ANOVA analysis. The best condition setting for parameters WEDM have been found. The significant interaction parameters produce a better optimization solution. The optimum cutting conditions in machining titanium alloys using WEDM was verified, meaning the model was reasonably accurate and the narrowed range factors can be used for machining. From the confirmation run, the percentage error between predicted and actual value for the responses were between 1.21 to 9.09 percent.

\section{ACKNOWLEDGEMENT}

The author would like to be obliged to University Malaysia Pahang for providing financial assistance under RDU170387.

\section{REFERENCES}

[1] Chiang, K. T. and Chang, F. P. (2006). Optimization of the WEDM process of particle-reinforced material with multiple performance characteristics using grey relational analysis. Journal of Materials Processing Technology, 180 (1-3), 96-101.

[2] Ho, K. H., Newman, S. T., Rahimifard, S. and Allen, R. D. (2004). State of the art in wire electrical discharge machining (WEDM). International Journal of Machine Tools and Manufacture, 44 (1213), 1247-1259.

[3] Kumar, A., Majumder, H., Vivekananda, K. and Maity, K. P. (2017). NSGA-II Approach for MultiObjective Optimization of Wire Electrical Discharge Machining Process Parameter on Inconel 718. Materials Today: Proceedings, 4(2), 2194-2202.

[4] Lodhi, B. K. and Agarwal, S. (2014). Optimization of machining parameters in WEDM of AISI D3 steel using taguchi technique. Procedia CIRP, 14, 194-199. 
[5] Maher, I., Sarhan, A. A. D. and Hamdi, M. (2014). Review of improvements in wire electrode properties for longer working time and utilization in wire EDM machining. International Journal of Advanced Manufacturing Technology, 76(1-4), 329-351.

[6] Mathew, B., Benkim and Babu, J. (2014). Multiple Process Parameter Optimization of WEDM on AISI304 Using Taguchi Grey Relational Analysis. Procedia Materials Science, 5, 1613-1622.

[7] Nourbakhsh, F., Rajurkar, K. P., Malshe, A. P. and Cao, J. (2013). Wire electro-discharge machining of titanium alloy. Procedia CIRP, 5, 13-18.

[8] Sivaprakasam, P., Hariharan, P. and Gowri, S. (2014). Modeling and analysis of micro-WEDM process of titanium alloy (Ti-6Al-4V) using response surface approach. Engineering Science and Technology, an International Journal, 17(4), 227-235.

[9] V, M. K., A, S. B., Venkatasamy, R. and Raajenthiren, M. (2010). Optimization of the WEDM Parameters on Machining Incoloy800 Super alloy with Multiple Quality Characteristics. International Journal of Engineering Science and Technology, 2(6), 1538-1547. 